Volume 1, Nomor 1, September 2020, 15-24

BEMAS: JURNAL BERMASYARAKAT

p ISSN 27455866 | e ISSN xxxx xxxx

\title{
PROGRAM PKM OPTIMALISASI WAKTU PEMROGRAMAN PADA PERANGKAT LUNAK TRUTOPS V 1.2.1 DI PT. UVW
}

\author{
Sulistya Agus Prabowo', Wilarso ${ }^{2 *}$, Asep Saepudin ${ }^{3}$ \\ ${ }^{(1)}$ Program Studi Teknik Mesin, Sekolah Tinggi Teknologi Muhammadiyah Cileungsi, Cileungsi, Bogor, Jawa \\ Barat, Indonesia 16820 \\ Email: sulistya.agus.prabowo@gmail.com,*wilarso@sttmcileungsi.ac.id, asep.saepudin@sttmcileungsi.ac.id
}

INFORMASI ARTIKEL

\section{Article History:}

Submission: $25-08-2020$

Revised: 31-08-2020

Accepted: 23-09-2020

Published: 30-09-2020

* Korespondensi:

Wilarso

wilarso@sttmcileungsi.ac.id

\begin{abstract}
ABSTRAK
Dalam pemrogram mesin produksi yang menggunakan software membutuhkan pengetahuan dan ketrampilan, supaya saat memrogram tidak mengalami kendala. Tujuan dari pengabdian ini adalah menentukan standar pemrograman Trutops yang merupakan perangkat lunak (software) yang dikembangkan oleh TRUMPF GmbH untuk membantu dalam menjalan mesin. TRUMPF menyediakan kepada pelanggan rangkaian perangkat lunak untuk menyelesaikan suatu proses pemesinan. Trutops telah dilengkapi beberapa aplikasi di seperti Trutops CAD, Trutops Nest, dan Trutops Punch/Laser (memasukan teknologi ke mesin punching/laser), dan aplikasi tersebut dalamnya saling berkesinambungan dengan mengintegrasikan semua langkah proses dalam produksi lembaran logam dalam satu sistem. Nesting adalah bahasa yang digunakan pengguna Trutops untuk membuat program agar mesin dapat beroperasi sesuai dengan program yang telah dibuat. Nesting bertujuan untuk memaksimalkan program yang telah dibuat agar pada proses pemesinan dapat berjalan secara maksimal, baik dari segi efisiensi waktu dan material. Artikel ini diharapkan dapat memberikan gambaran mengenai efisiensi waktu dalam pembuatan program dengan perangkat lunak Trutops V1.2.1. Dari bahasa pemrograman ini nanti akan di aplikasikan dalam bentuk pelatihan ke Siswa SMK, agar pengetahuan dalam hal pemrograman mesin produksi, supaya saat lulus sekolah nanti bisa langsung diserap oleh dunia
\end{abstract} industri.

Kata Kunci: TRUMPF GmbH, Trutops, Software, Nesting

OPTIMIZATION OF PROGRAMMING TIME IN TRUTOPS V 1.2.1 SOFTWARE

ABSTRACT

In a production machine programmer who uses software requires knowledge and skills, so that when programming does not experience problems. The aim of this service is to determine the Trutops programming standard which is a software (software) developed by TRUMPF GmbH to assist in running the machine. TRUMPF provides customers with the software suite to complete a machining process. Trutops has several applications in such as Trutops CAD, Trutops Nest, and Trutops Punch / Laser (incorporating technology into punching/laser machines), and the applications are interconnected by integrating all process steps in sheet metal production in one system. Nesting is the language used by Trutops users to create programs so that the machine can operate according to the program that has been created. Nesting aims to maximize the program that has been made so that the machining process can run optimally, both in terms of time and material efficiency. This article is expected to provide 
an overview of time efficiency in programming with the Trutops V1.2.1 software. This programming language will later be applied in the form of training to vocational students, so that knowledge in production machine programming, so that when graduating from school, can be directly absorbed by the industrial world.

Keywords: TRUMPF GmbH, Trutops, Software, Nesting

\section{PENDAHULUAN}

Di dalam dunia industri 4.0 seperti sekarang ini banyak sekali jenis mesin yang digunakan untuk memproduksi suatu barang, baik mesin buatan lokal maupun mancanegara [1]. Setiap tahun negaranegara pembuat mesin selalu menghadirkan fitur-fitur terbaru, baik desain, fungsi, teknologi, kemudahan pemakaian, dan kemudahan pemeliharaan untuk mesin yang dijual ke pasaran.

TRUMPF GmbH merupakan perusahaan manufaktur mesin industri dari negara Jerman. Banyak mesin-mesin industri baja lembaran (sheet metal) yang telah diproduksi oleh TRUMPF. Adapun jenis mesin yang telah diproduksi adalah Laser, Turret Punch, Bending dan Laser Tube. Semua mesin yang dibuat dibekali dengan sebuah perangkat lunak bernama TRUTOPS yang bertujuan untuk memudahkan dalam pengoperasian.

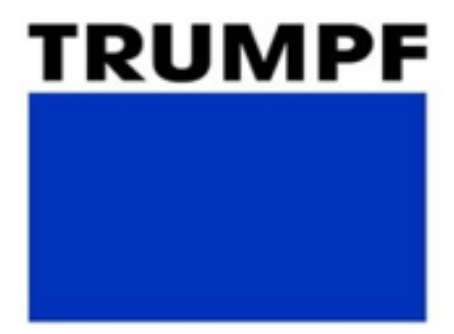

Gambar 1. Logo brand TRUMPF.

TRUTOPS adalah perangkat lunak desain 2 dimensi yang memudahkan pengguna untuk menjalankan mesin dari pabrikan TRUMPF. Dalam penggunaanya, trutops berbeda dengan aplikasi Solidworks, Autocad, Catia, dan lain-lain yang dapat membuat desain atau tampilan 3 dimensi, Trutops hanya dapat digunakan untuk pemrograman mesin. Didalam Trutops terdapat 3 aplikasi urutan pengerjaan program yang yang dimulai dari aplikasi Trutops CAD (Computer aided Design) disini langkah awal sebuah part digambar, kemudian dilanjutkan dengan aplikasi Trutops Nest dimana part sudah di dimasukan dan diatur ke dalam lembaran pelat (material dan jumlah pelat yang ditentukan), tahapan terakhir sebelum program dijalankan adalah pemrograman dengan menggunakan aplikasi Trutops Punch [2], lembaran pelat yang telah diisi benda kerja (part) dan memasukkan teknologi pemrosesan akan memotong bagian yang diinginkan dan program $\mathrm{NC}$ yang kemudian dikirim ke mesin. Kata NC (Numerical Control) berasal dari bahasa Inggris yang berarti kontrol numerik [3] . Inti dari sistem ini adalah menyediakan semua data untuk diproses oleh mesin dalam bentuk numerik. Sistem mengontrol, memproses data ini dan mentransmisikannya disesuaikan dengan aktuator pada mesin, setelah selesai program siap dijalankan ke mesin, baik mesin punching TC5000 maupun yang lainnya.

Nesting adalah bahasa yang digunakan pengguna TRUTOPS untuk membuat program agar mesin dapat beroperasi sesuai dengan program yang telah dibuat sebelumnya [4]. Banyak cara dalam membuat program (Nesting) agar mesin dapat beroperasi secara maksimal baik dengan cara pemrograman otomatis atau manual. Dalam nesting otomatis maupun manual punya kelebihan dan kekurangan tersendiri.

Banyak faktor yang dapat mempercepat suatu pekerjaan yang dilakukan oleh mesin [5], salah satu yaitu manajemen waktu yang mempengaruhi kinerja mesin punching TC 5000 [6], dimana kecepatan waktu nesting akan sangat berpengaruh terhadap jumlah material yang dikerjakan mesin tersebut, semakin cepat waktu nesting maka semakin banyak jumlah material yang digunakan dan semakin cepat pula pekerjaan akan selesai. 
Tujuan dari PkM ini adalah untuk memberikan pelatihan program TRUTOPS kepada siswa SMK dalam hal program mesin produksi.

Masalah yang sering terjadi pada perusahaan ini sering tidak optimalnya waktu pemrograman pada perangkat lunak TRUTOPS, sehingga membutuhkan waktu yang lama.

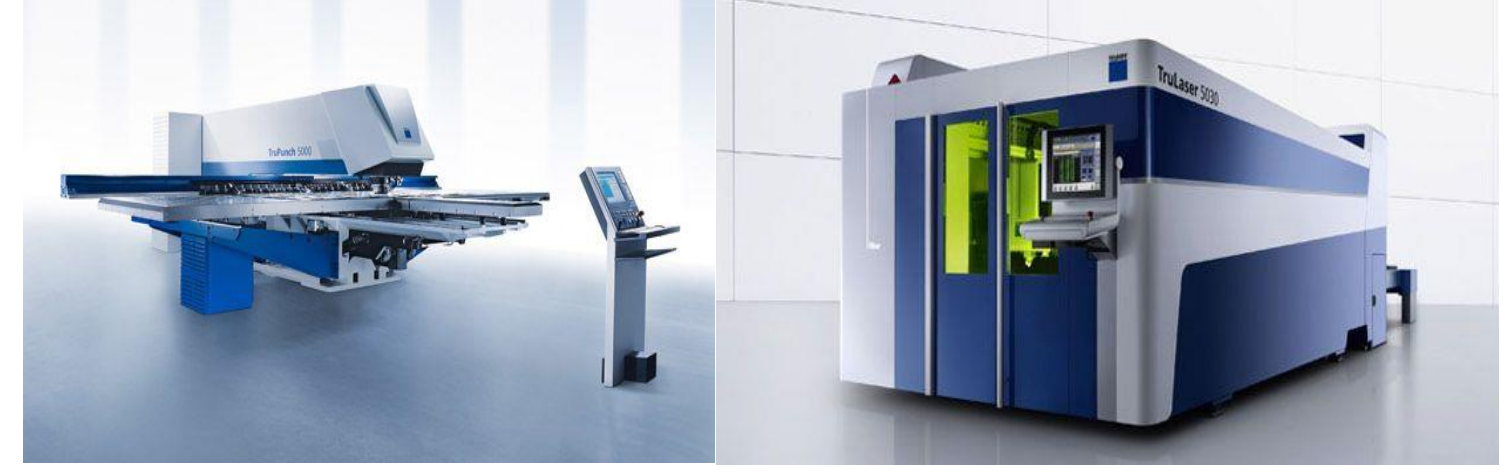

Gambar 2. Mesin Trupunch 5000 dan Mesin Trulaser 503

\section{METODE PELAKSANAAN PENGABDIAN}

Berdasarkan permasalahan yang dijelaskan di hipotesis penelitian [6], maka teknik yang digunakan dalam penelitian ini menggunakan metode interview. Interview dilakukan kepada responden yang telah bekerja selama 7 tahun di bidang pemrograman dengan menggunakan perangkat lunak TRUTOPS. Penelitian ini dilakukan untuk mengetahui optimalisasi waktu pemrograman dengan cara otomatis dengan pemrograman secara manual [7].

\section{HASIL DAN PEMBAHASAN PENGABDIAN}

\subsection{Langkah-Langkah Pelaksanaan PkM}

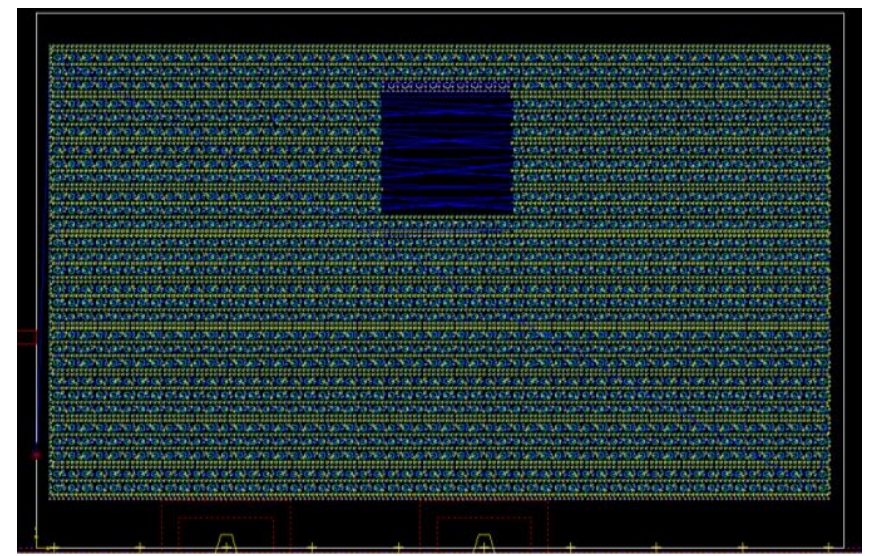

Gambar 3. Benda kerja untuk pemrograman otomatis. 
Optimalisasi Waktu Pemrograman Pada Perangkat Lunak Trutops V 1.2.1

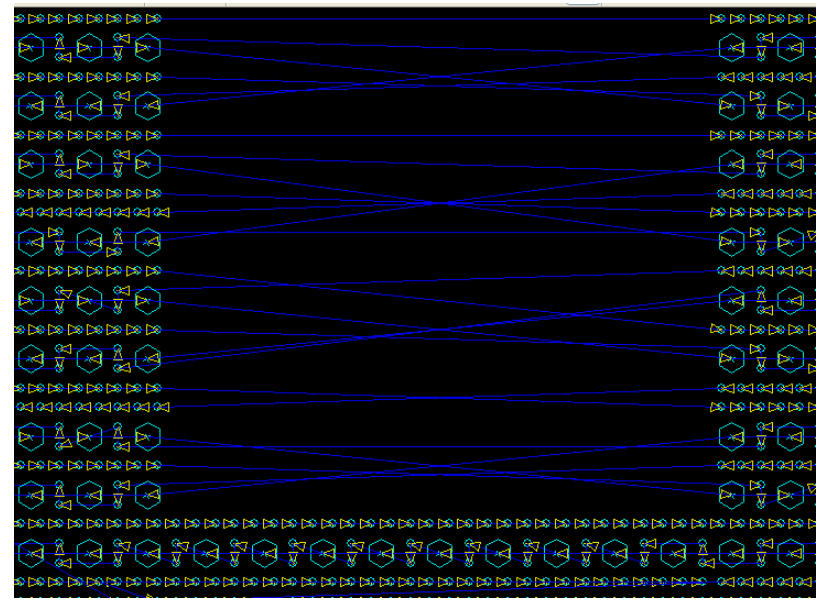

Gambar 4. Benda kerja yang diperbesar untuk pemrograman otomatis.

Benda kerja dengan pemrograman secara otomatis terlihat arah jalan pemotongan tidak beraturan.

Tabel 1. Program data dan hasil data pemrograman secara otomatis

\begin{tabular}{|c|c|}
\hline $\begin{array}{l}\text { SET-UP SCHEDULE } \\
\text { GENERAL DATA }\end{array}$ & $\begin{array}{l}\text { 10.03.2020 } \\
\text { TruTops Punch } \\
\text { V07.01.01 }\end{array}$ \\
\hline MACHINE: & TruPunch 5000 (S01) - TYPE: 1 (2500.0 x $1250.0 \mathrm{~mm})$ \\
\hline CONTROL: & Sin 840D VARIANT: 1 \\
\hline \multicolumn{2}{|l|}{ FIRMA: } \\
\hline \multicolumn{2}{|l|}{ JOB NAME: } \\
\hline NC PROGRAM PATH: & D:IUser1ISS YANTOINEST_OTOMATIS.LST \\
\hline PROGRAM NAME: & NEST_OTOMATIS (SS_YANTO_57) \\
\hline MATERIAL ID: & $1.4301-10(1.4301)$ \\
\hline \multicolumn{2}{|l|}{ STORAGE ITEM DESIGNATION: } \\
\hline BLANK: & $1220 \times 810 \times 1 \mathrm{~mm}$ \\
\hline WEIGHT: & $7.81 \mathrm{~kg}$ \\
\hline MACHINING TIME: & $0: 22: 16[\mathrm{~h}: \min : \mathrm{s}]$ \\
\hline STORAGE REQUIREMENT: & 231087 CHARACTERS \\
\hline LASER TOTAL CUTTING LENGTH: & $0.000 \mathrm{~mm}$ \\
\hline NUMBER OF PROGRAMME RUNS: & 1 \\
\hline SCRAP: & $20.01 \%$ \\
\hline
\end{tabular}

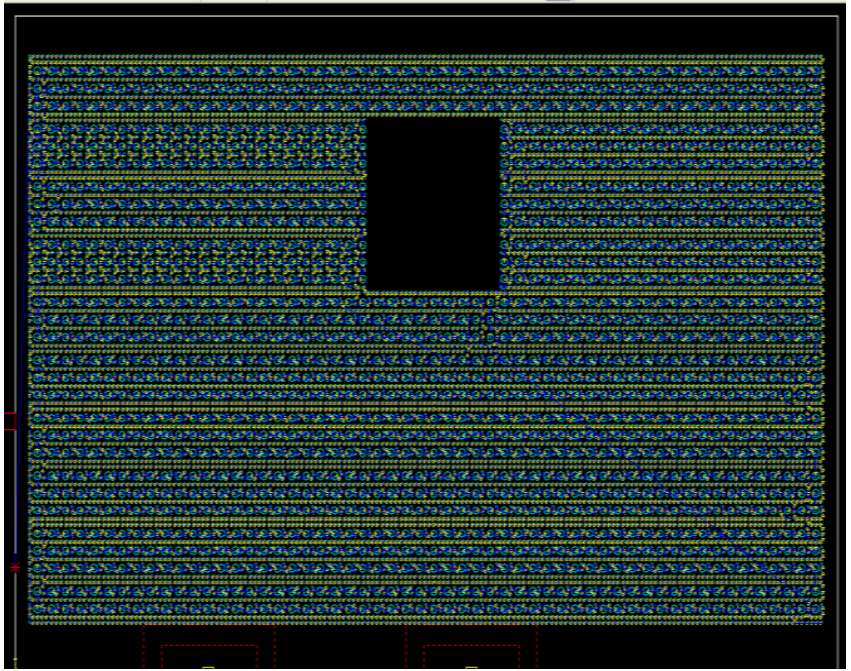

Gambar 5. Benda kerja untuk pemrograman manual. 


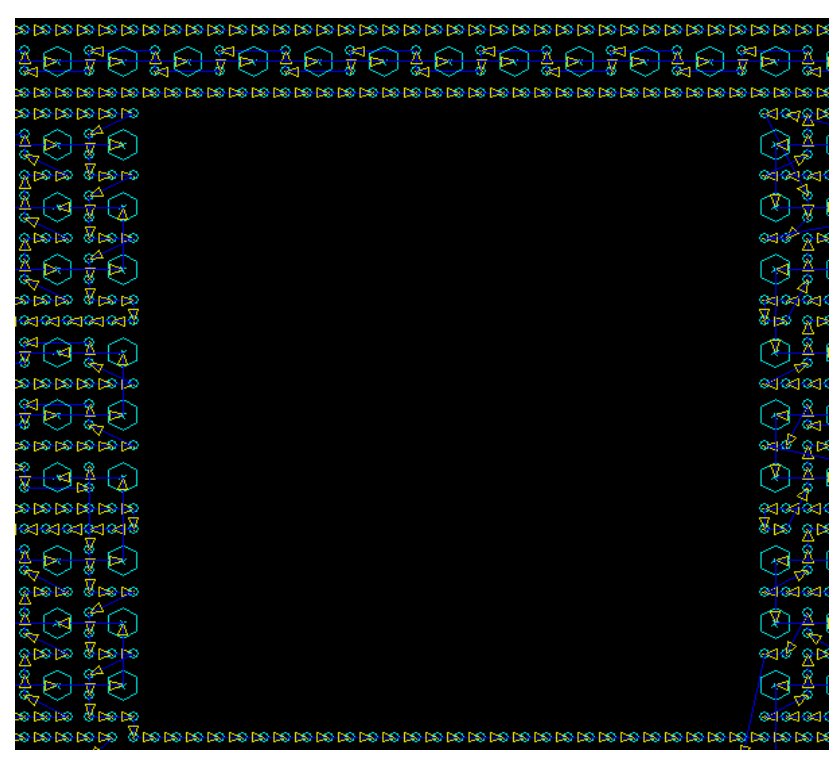

Gambar 6. Benda yang diperbesar untuk pemrograman manual.

Benda kerja dengan pemrograman secara manual terlihat arah jalan pemotongan beraturan.

Tabel 2. Program data dan hasil data pemrograman secara manual

\begin{tabular}{|c|c|}
\hline $\begin{array}{l}\text { SET-UP SCHEDULE } \\
\text { GENERAL DATA }\end{array}$ & $\begin{array}{l}\text { 10.03.2020 } \\
\text { TruTops Punch } \\
\text { v07.01.01 }\end{array}$ \\
\hline MACHINE: & TruPunch 5000 (S01) - TYPE: 1 (2500.0 x $1250.0 \mathrm{~mm})$ \\
\hline CONTROL: & Sin 840D VARIANT: 1 \\
\hline \multicolumn{2}{|l|}{ FIRMA: } \\
\hline \multicolumn{2}{|l|}{ JOB NAME: } \\
\hline NC PROGRAM PATH: & D:IUser1ISS YANTOINEST_MANUAL.LST \\
\hline |PROGRAM NAME: & UNST_MANUAL (SS_YANTO_57) \\
\hline MATERIAL ID: & $1.4301-10(1.4301)$ \\
\hline \multicolumn{2}{|l|}{ STORAGE ITEM DESIGNATION: } \\
\hline BLANK: & $1220 \times 810 \times 1 \mathrm{~mm}$ \\
\hline WEIGHT: & $7.81 \mathrm{~kg}$ \\
\hline MACHINING TIME: & $0: 21: 57$ [h:min:s] \\
\hline |STORAGE REQUIREMENT: & 228374 CHARACTERS \\
\hline LASER TOTAL CUTTING LENGTH: & $0.000 \mathrm{~mm}$ \\
\hline NUMBER OF PROGRAMME RUNS: & 1 \\
\hline SCRAP: & $20.01 \%$ \\
\hline
\end{tabular}

Pemrograman manual pada benda kerja dengan jumlah, material dan ketebalan yang sama, diketahui adanya perbedaan waktu yaitu sebesar 19 detik lebih cepat dibandingkan dengan pemrograman otomatis. Ini memungkinkan waktu dapat terbuang sangat banyak jika dikerjakan dalam jumlah yang banyak (mass product)[8].

\subsection{Hasil Pelaksanaan PkM}

Dalam memprogram Trutops harus melewati tiga urutan pengerjaan yang saling mengikuti. Di aplikasi Trutops CAD, di dalam aplikasi ini dapat menggambar dan merubah potongan part yang diinginkan. Setelah part sudah ditentukan ukuran dan siap proses kemudian dilanjutkan ke Trutops Nest. Dimana part dimasukkan ke dalam pelat baja lembaran. Pada langkah terakhir pemrograman terdapat aplikasi Trutops Punch, didalamnya menentukan teknologi (pemilihan alat potong dan urutan jalan alat potong tersebut) pemrosesan yang akan memotong bagian yang diinginkan dan Trutops Punch menuliskan program NC, yang kemudian dikirim ke mesin. Trutops memandu seluruh prosedur 
pengerjaan, dimulai dari pembuatan gambar hingga mengubah menjadi NC (Numerical Control) yang lengkap dan bisa dikerjakan di mesin.

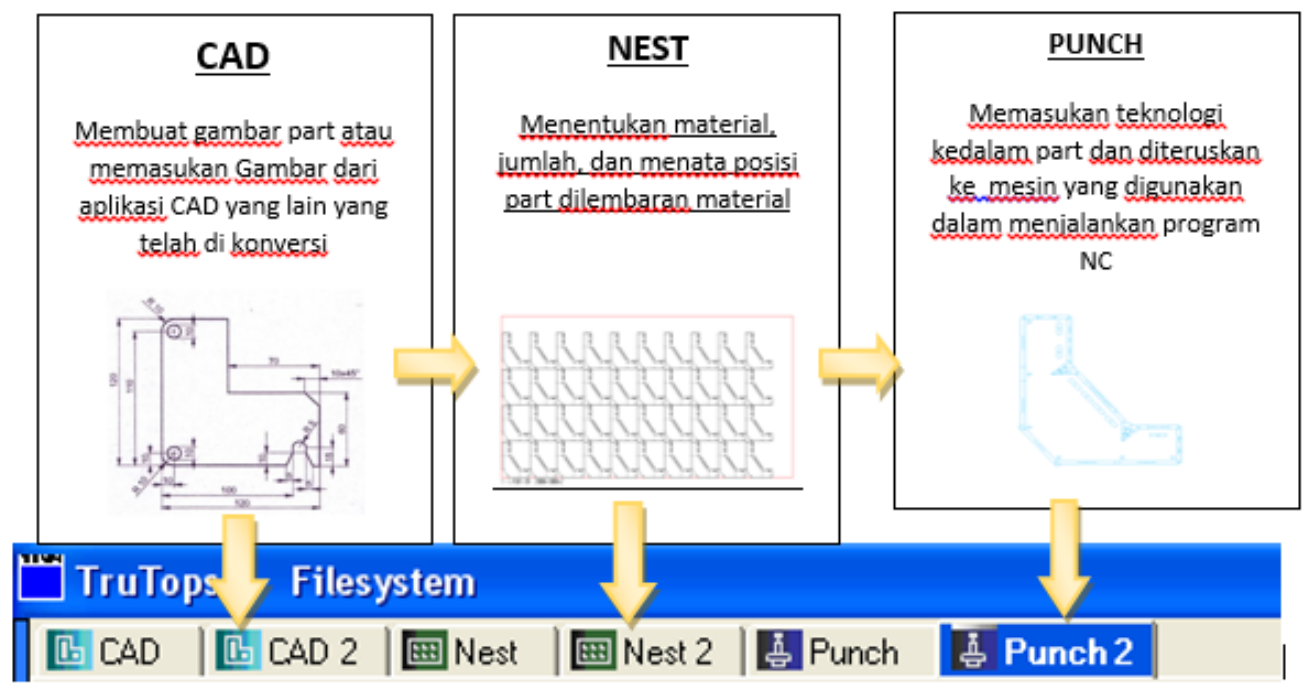

Gambar 7. Tahapan Proses Pemrograman yang dimulai dari Trutops CAD, Trutops Nest, dan terakhir Trutops Punch/Laser

Tabel 3. Tipe file yang berada dalam program Trutop

\begin{tabular}{lll}
\hline Aplikasi & File Format & Catatan \\
\hline Trutops CAD & $\bullet$ Nama part.GEO & $\bullet$ Geometri \\
& $\bullet$ Nama alat.WZG & $\bullet$ Tools \\
Trutops Nest & $\bullet$ Nama lembaran_urutan_angka_.TAF & $\bullet$ Lembaran pelat \\
& $\bullet$ Nama_Pekerjaan.JOB & $\bullet$ Program JOB \\
Trutops Punch & $\bullet$ Nama File.GMT & $\bullet$ Geometri dengan \\
& $\bullet$ Nama File .TMT & \\
& $\bullet$ Nama Lembaran.LST & $\bullet$ Leknologi \\
& & \\
& & $\bullet$ teknologi \\
\hline
\end{tabular}

Setiap aplikasi mempunyai format file yang berbeda-beda dari GEO yang mengartikan bahwa gambar masih berbentuk part, WZG adalah gambar part dan disimpan untuk tool (alat mesin punching TC5000), TAF merupakan file yang ekstensi didapat setelah part diatur dalam lembaran pelat. JOB adalah ekstensi dari file taf yang lebih dari 1 lembar dengan beberapa parts berbeda yang diatur. GMT adalah bentuk ekstensi dari part yang telah dimasukan teknologi berupa tool yang telah disematkan ke part tersebut. TMT ekstensi dari TAF yang yang telah dimasukan teknologi sama seperti GMT namun yang membedakan adalah Pelat lembaran berisi part yang telah dimasukan teknologi. Dan LST adalah ekstensi berisi program NC yang siap dijalankan pada mesin TC5000. 


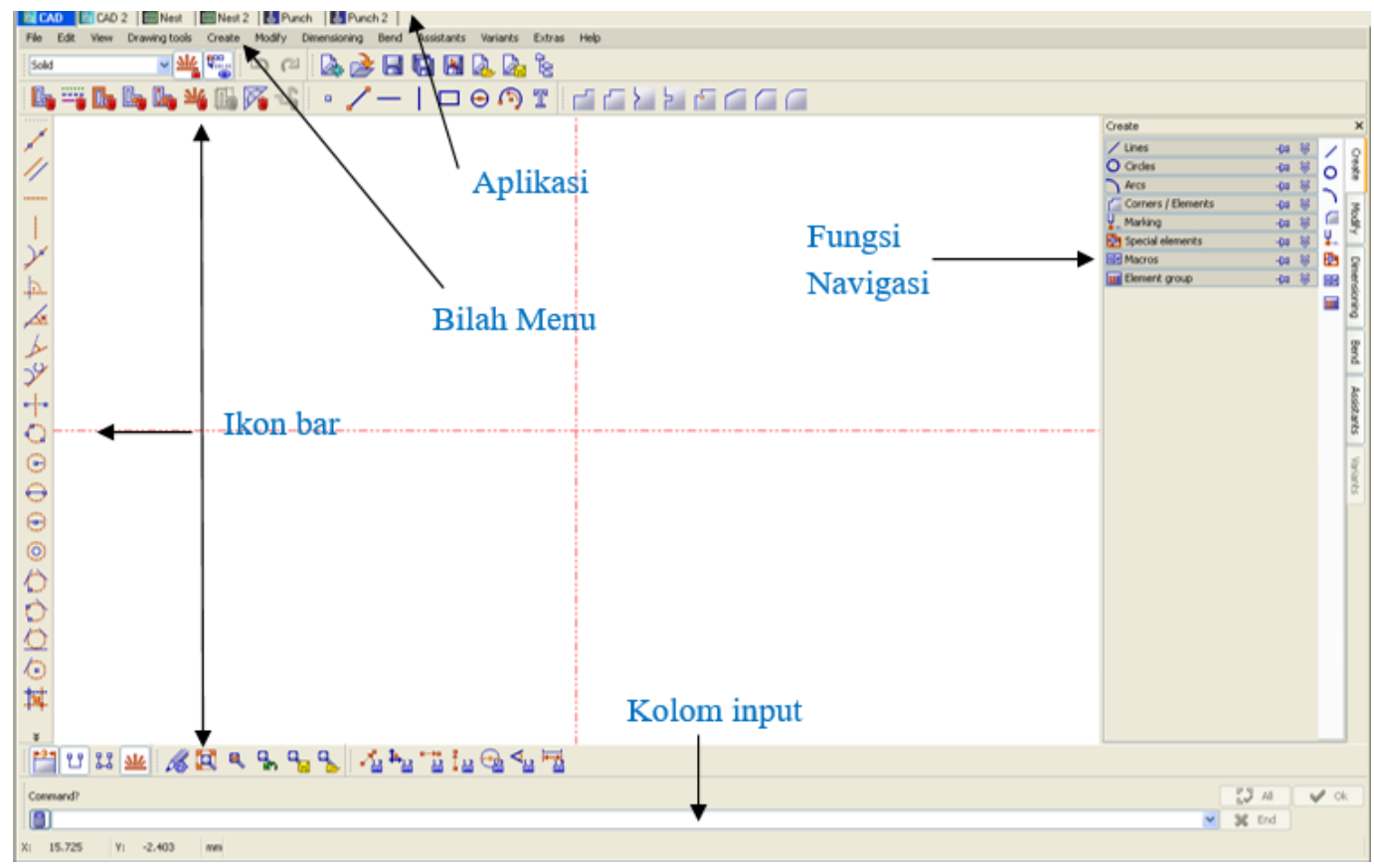

Gambar 8. Tampilan di Aplikasi Trutops CAD

\subsection{Trutops NEST}

Trutops Nest adalah proses kedua yang harus dilakukan setelah Trutops CAD. Disini menerangkan tentang informasi tentang jumlah part, tebal, ukuran material dan bahan yang akan digunakan. Jarak antar part, baik part dengan part maupun part dengan batas material juga diatur di disini. Pengaturan jarak dapat dibuat secara otomatis, tetapi jika disetel secara otomatis maka scrap atau sisa dari bahan sangat banyak yang tidak terpakai. Berbeda jika melakukannya manual, kita dapat meminimalisir penggunaan material hingga beberapa persen lebih hemat. Jika part berbentuk lingkaran atau tidak simetris sangat dianjurkan untuk menata secara manual.

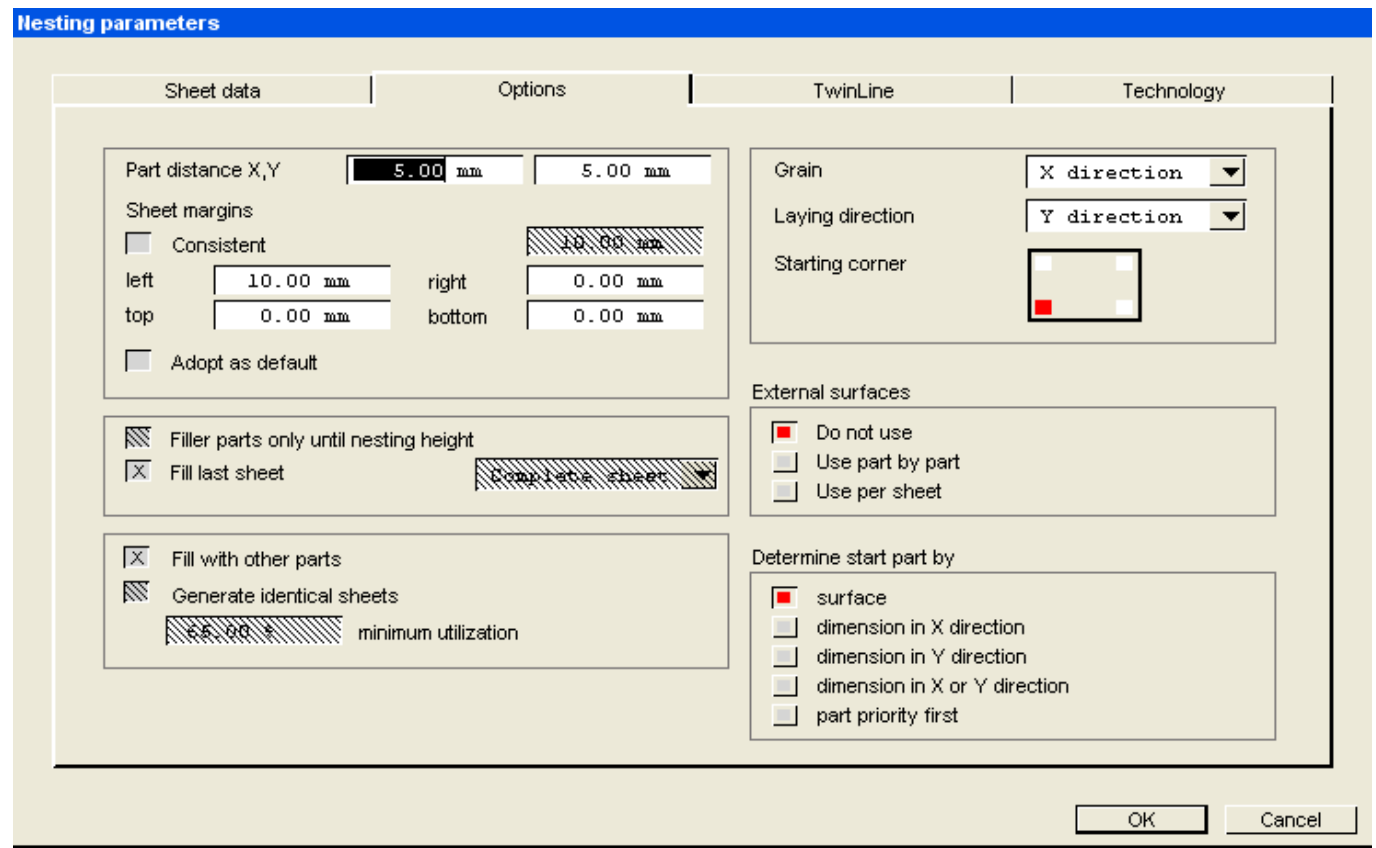

Gambar 9. Parameter yang digunakan dalam penataan part

Fungsi dari parameter sendiri adalah untuk mengatur jarak antar part, batas antara pinggir pelat (baik atas, kanan, kiri, dan bawah) lembaran dengan part, dan memulai menata part dari ujung sumbu 
$\mathrm{x}$ atau sumbu y pelat. Dalam praktiknya parameter ini paling sering digunakan karena merupakan yang tercepat dan efisien.

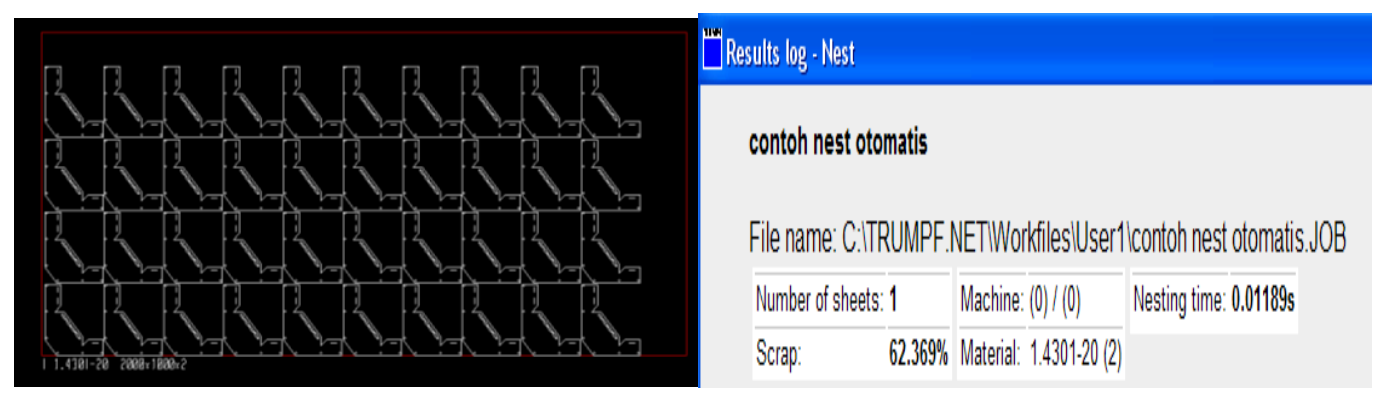

Gambar 10. Sistem penataan secara otomatis

Penataan benda kerja pada lembaran logam dapat memilih beberapa cara penyusunan otomatis. Default: metode bersarang (nesting) standar. Jika memiliki benda kerja sederhana, cara tercepat adalah menumpuknya di lembaran logam. Pengembang menggunakan metode penataan ini paling sering, karena dengan metode ini hasil penataan benda kerja lebih cepat dan efisien. Single Part: mode ini disesuaikan untuk menumpuk potongan identik (part yang sama bentuknya).
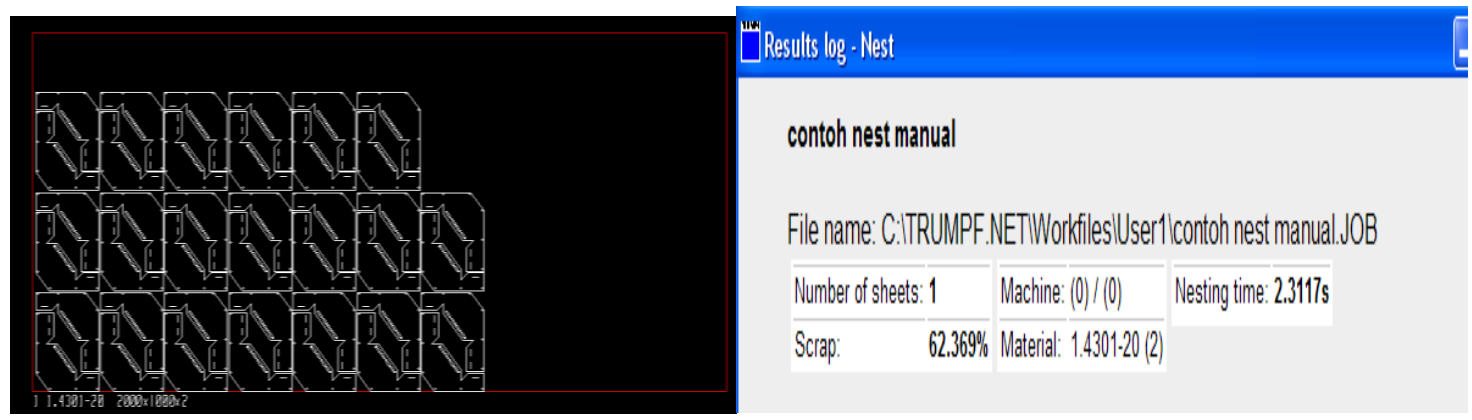

Gambar 11. sistem penataan secara manual dan hasil

Dalam mode penyusunan ini, programmer secara manual menerapkan benda kerja ke lembaran logam. Programmer memiliki kemampuan untuk memutar, mirror, menyalin dan memindahkan gambar melintasi lembaran logam untuk mendapatkan efisiensi sebaik mungkin. Jumlah potongan yang diinginkan di monitor di layar, yang selalu disegarkan jika kita melakukan perubahan.

Perbedaan yang dapat diketahui adalah, dengan jumlah parts yang sama dan sisa bahan yang sama dapat dikatakan dalam penataan secara manual masih bisa ditambahkan beberapa parts lagi. Dari sini juga dilihat perbedaan nesting time, jika menggunakan penataan secara manual maka waktu yang digunakan lebih besar dengan penataan secara otomatis.

\subsection{Trutops Punch}

Setelah selesai menggambar dan menata benda kerja, Trutops Punch adalah langkah terakhir dalam sebuah pemrograman perangkat lunak Trutops sebelum memasuki proses machining [9]. Fungsi utama aplikasi ini adalah memasukan teknologi berupa memasukan alat (tool) yang akan dipakai dalam benda kerja dalam pelat lembaran. Dalam pengerjaan ini dapat mengambil dari beberapa file pemrosesan ekstension dari GEO dan TAF. Disini juga dapat memindah klem penjepit lembar bahan agar bahan tidak terlepas. 


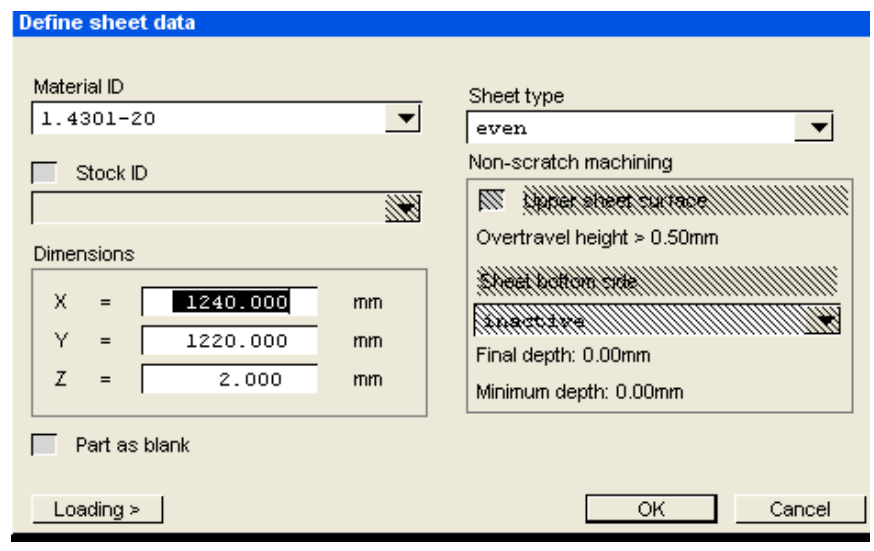

Gambar 12. Parameter material jika file GEO dimasukan ke TRUTOPS PUNCH

Dalam pengerjaan di aplikasi Trutops Punch, jika mengambil file GEO maka secara otomatis akan keluar parameter untuk menentukan ukuran, tebal dan bahan material yang akan digunakan. Berbeda jika file yang dimasukan berupa file TAF, maka file tersebut langsung dapat dimasukan tanpa harus merubah parameter, dikarenakan pada Trutops Nest sudahdi atur penataan baik bahan, jumlah benda kerja dan ukuran material yang dipakai.

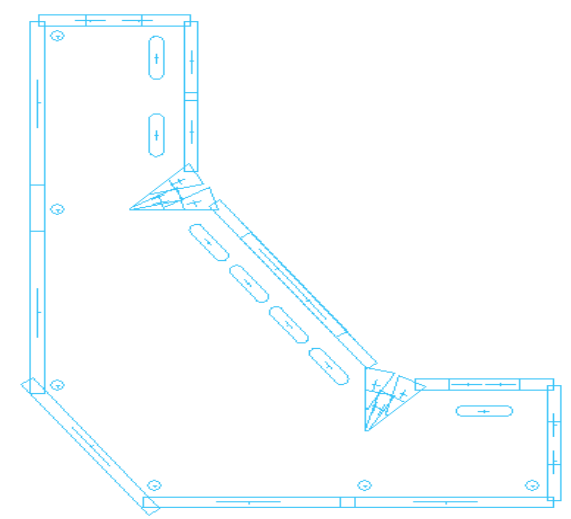

Gambar 13. Benda kerja yang telah disimpan dalam ekstensi TMT

Dalam file ekstensi dapat terlihat alat (tool) yang dipakai. Biasanya pemakaian dengan format TMT digunakan pada benda kerja yang sering dipakai, dikarenakan dengan menyimpan file TMT maka tidak perlu lagi mencari alat yang digunakan untuk memotong.

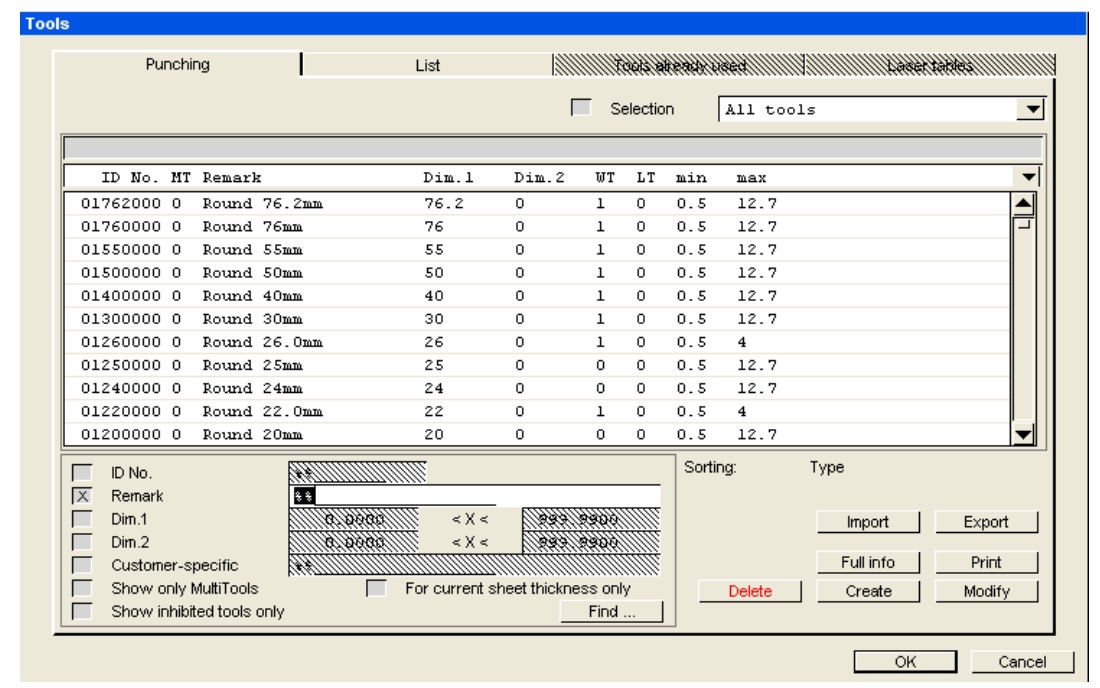




\section{Gambar 14. Database alat yang digunakan pada teknologi Punch}

Dalam pemrograman di Trutops Punch [10], yang paling penting adalah memasukan tool ke benda kerja dengan tujuan membentuk benda kerja sesuai gambar kerja, disini seorang programer diharuskan mengetahui tool apa saja yang digunakan dalam setiap pemrosesan, karena tidak semua tool dapat dipakai dikarenakan slot yang tersedia di dalam mesin hanya 18 slots.

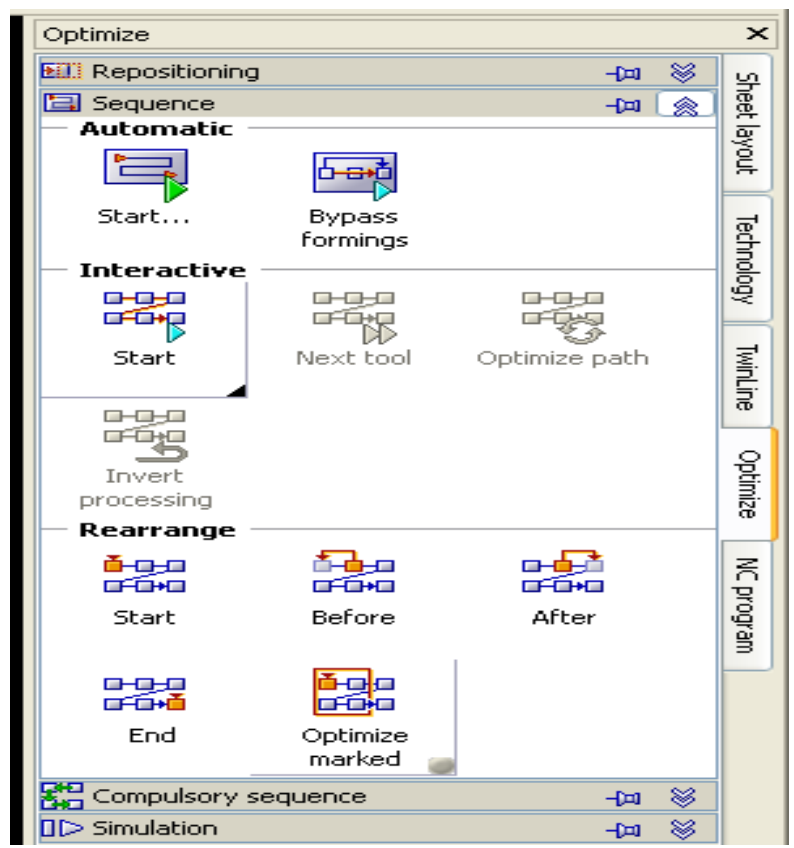

Gambar 15. Ikon untuk mengatur arah jalannya sebuah tool.

Setelah selesai memasukan tool maka yang perlu dilakukan adalah menentukan arah jalannya tool itu sendiri. Pertama-tama yang dilakukan adalah memasukan tools paling kecil sampai dengan tools yang paling besar sampai selesai. Dalam menentukan arah jalannya tools dapat dilakukan dengan dua cara yaitu secara manual ataupun otomatis.

\section{SIMPULAN}

Dari pelaksanaan PkM yang dilakukan disalah satu PT. UVW, perusahaan senang dari mahasiswa STTMC yang telah membantu pemrograman TRUTOPS dengan baik. Dari hasil PkM yang didapat di setiap pemrograman perlu diperhatikan jalannya sebuah tool dikarenakan untuk setiap lembar kerja yang berbeda perlu perlakuan berbeda. Secara umum pemrograman dengan otomatis mendapatkan hasil yang lebih cepat dan optimal, seperti pada jumlah parts yang sama dan sisa bahan yang sama dapat dikatakan dalam penataan secara manual membutuhkan waktu 2.3117 second sedangkan penataan otomatis hanya membutuhkan waktu 0.01189 second sedangkan pada Pemrograman manual pada benda kerja dengan jumlah, material dan ketebalan yang sama, diketahui adanya perbedaan waktu yaitu sebesar 19 detik lebih cepat dibandingkan dengan pemrograman otomatis, ini perlunya ketelitian seorang programmer dimana harus melihat apakah arah jalannya program sudah seperti yang diinginkan atau belum.

\section{UCAPAN TERIMA KASIH}

Ketua STTMC yang telah mensupport pelaksanaan PkM dan Ketua LPPMPK yang telah membimbing kegiatan penyusuan penulisan artikel PkM.

\section{DAFTAR PUSTAKA}

[1] A. O. Riordan, J. Coady, T. Newe, and G. Dooly, "'Industry 4 .0 : Pillars for Smart Manufacturing - A Review,” Ind. 4.0 Summit, no. February, pp. 110-116, 2019.

[2] T. B. Page, "Well positioned?"

[3] H. Yuan, T. Wu, M. Li, B. Liang, and Q. Zhang, "Numerical control press design based on quantitative evaluation of appearance area features," IOP Conf. Ser. Mater. 
Sci. Eng., vol. 892, p. 012067, 2020.

[4] D. Darmawan, “済無No Title No Title,” J. Chem. Inf. Model., vol. 53, no. 9, pp. 16891699, 2019.

[5] S. Patil, S. Pawar, A. Karanke, A. Parkhi, and A. Thombre, "Tool life management for cnc machine," Int. Res. J. Eng. Technol., vol. 4, no. 4, pp. 441-445, 2017.

[6] M. Karthick, M. Sundarraj, and T. Raja, "Design and control of ATC for shorter time interval in CNC machines," Int. J. Mech. Eng. Technol., vol. 8, no. 3, pp. 77-88, 2017.

[7] M. F. Abdulla, "An Efficient Manual Optimization for C Codes," vol. 3, no. 2, 2010.

[8] H. I. Abdel-Shafy and M. S. M. Mansour, "Solid waste issue: Sources, composition, disposal, recycling, and valorization," Egypt. J. Pet., vol. 27, no. 4, pp. 1275-1290, 2018.

[9] W. Bin Rashid and S. Goel, "Advances in the surface defect machining (SDM) of hard steels," J. Manuf. Process., vol. 23, pp. 37-46, 2016.

[10] G. G. Wang and S. Q. Xie, "Optimal process planning for a combined punch-and-laser cutting machine using ant colony optimization," Int. J. Prod. Res., vol. 43, no. 11, pp. 2195-2216, 2005. 